\title{
РОЗРАХУНОК КУЛАЧКОВОГО МЕХАНІЗМУ ПЕРІОДИЧНОГО ПОВОРОТУ
}

( Ю. О. Шостачук, К.т.н., доцент, Д. С. Гриценко, аспірант, НТУУ «КПІ», Київ, Україна

\section{Рассмотрена методика синтеза кулачкового механизма периодического поворота.}

\section{It is considered the synthesis of the cam mechanism of periodic turn.}

\section{Постановка проблеми}

Для відтворення періодичного руху в транспортувальних пристроях поліграфічних машин широкого використовуються кулачкові механізми. Впровадження таких механізмів при розробці нового і модернізації існуючого обладнання вимагає спрощеної методики їх розрахунку. Це можливо при використанні нових сучасних програмних продуктів.

Транспортувальні пристрої періодичного руху повинні забезпечувати плавність періодичного руху, задане співвідношення періодів вистою та робочого руху виконавчих елементів, а також абсолютну точність позиціонування виробів відносно виконавчих ланок. Кулачкові механізми періодичного повороту задовольняють таким вимогам.

Розрахунок профілю кулачка з врахуванням всіх необхідних умов супроводжується складними розрахунками.

Розробка спеціального програмного продукту з розрахунку кулачкових механізмів дозволяє спростити процес синтезу кулачкового механізму, суттєво зменшує вірогідність появи похибок, заощаджує час, а також дозволяє оптимізувати конструктивні параметри.

\section{Аналіз попередніх досліджень}

Використання у поліграфічних машинах кулачкових механізмів обумовлено необхідністю реалізації циклічних технологічних операцій. Крім того, кулачкові механізми періодичного повороту дозволяють реалізувати більш сприятливі у динамічному відношення закони періодичного руху веденої ланки, змінити співвідношення періодів повороту та вистою, а також забезпечити беззазорну фіксацію веденої ланки у період вистою.

Ці механізми характеризуються нерівномірним рухом ведених мас і відповідно змінною дією сил інерції. Сьогодні існують методики і програми розрахунку окремих параметрів кулачкових механізмів класичного вигляду без врахування специфіки конструкції кулачкових механізмів періодичного повороту [1].

В статтях [2, 3] показана можливість використання кулачко- 


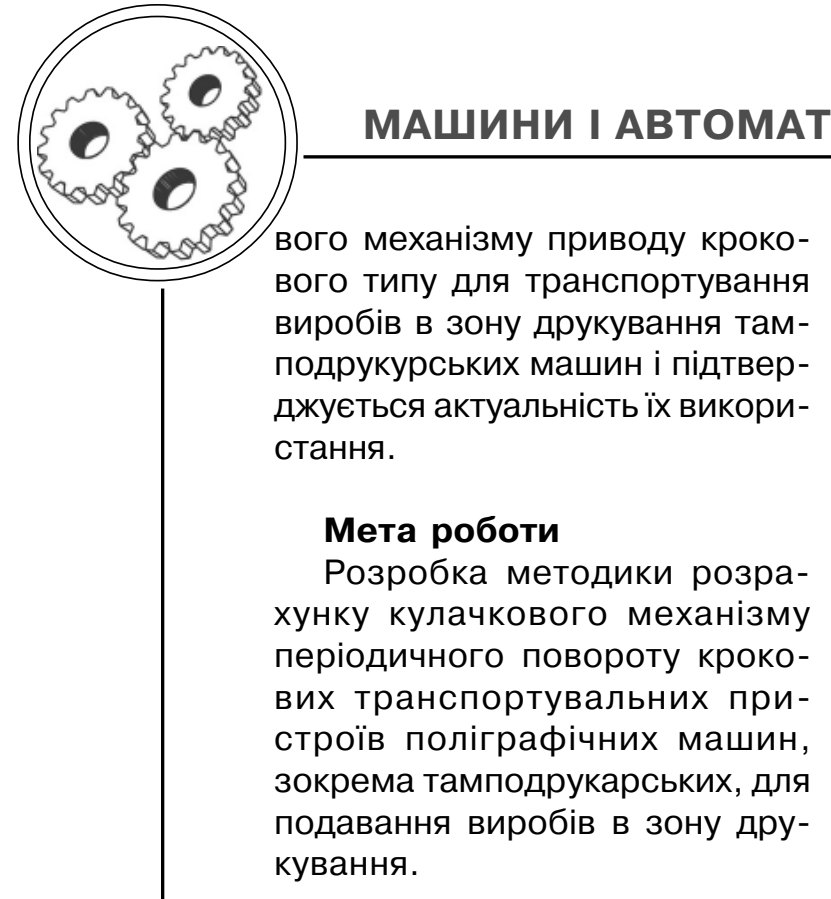

\section{Результати проведених досліджень}

Визначення схеми і параметрів кулачкового механізму

Особливістю кулачкових механізмів періодичного повороту $€$ те, що рух виконавчим ланкам передається на певній ділянці кутового переміщення профілю кулачка з подальшою фіксацією виконавчих елементів у період вистою, що забезпечує на цьому проміжку абсолютну точність виконання технологічного процесу. Схема механізму періодичного повороту представлена на рис 1.

Кулачок 2, закріплений на головному валу 1 , повертає на певній ділянці свого профілю виконавчу систему, яка складається 3 закріпленого на валу 5 коромислового диску 4 із закріпленими на ньому роликами 3.

Для розрахунку кінематичних параметрів механізму конструктивно задаємо фазовий кут кулачка (ц), кут повороту коромислового диску $\left(\left\ulcorner_{y}\right)\right.$, частоту обертання головного валу $(\mathrm{n})$, діаметр головного валу $\left(\mathrm{d}_{\mathrm{gv}}\right)$, діаметр веденого валу $\left(d_{v v}\right)$, відстань між центрами кулачка і диска (b), радіус коромислового диску (I), визначаємо закон

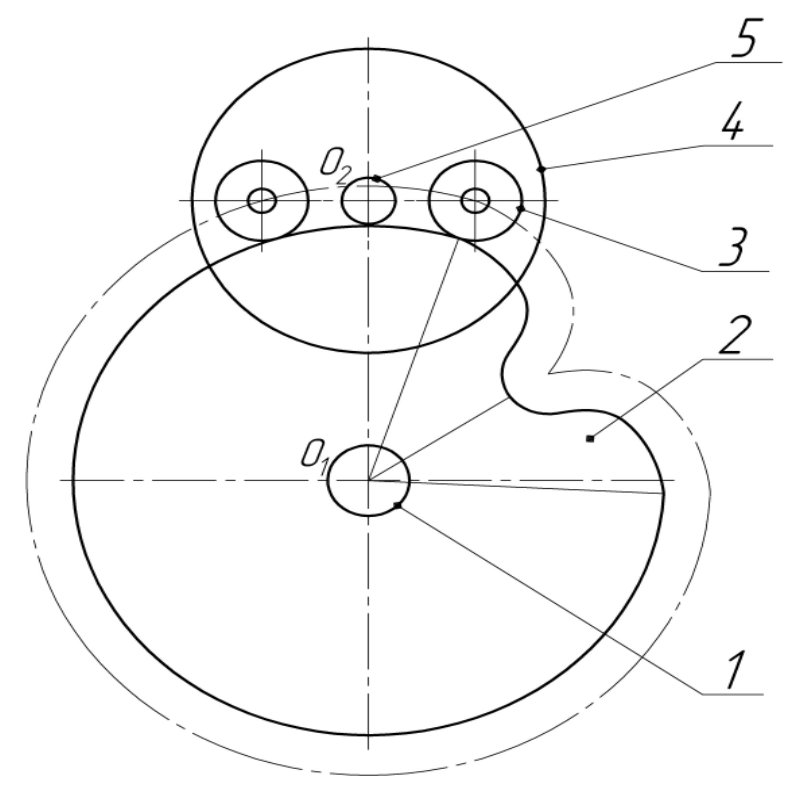

Рис. 1. Основні елементи кулачкового механізму періодичного повороту 
періодичного руху, максимальні навантаження на валу коромислового диску.

Для подальшого розрахунку геометричних параметрів механізму визначаємо максимальні крутні моменти на головному та веденому валах. Крутний момент на веденому валу визначається як сума максимальних приведених моментів від дії статичних і динамічних сил в системі:

$$
\mathrm{M}_{\Sigma \max }=\mathrm{M}_{\mathrm{st}}+\mathrm{M}_{\mathrm{in}},
$$

де $\mathrm{M}_{\mathrm{st}}$ - статичний момент, вираховується як сумарний приведений момент від технологічних сил; сил ваги; зусиль при деформації пружин, ресор, пневмоциліндрів тощо; моментів від сил тертя тощо, сумарний момент від сил інерції $\left(\mathrm{M}_{\mathrm{in}}\right)$.

Теоретичний профіль таких кулачкових механізмів на ділянках розбігу і вибігу представляє собою епіциклоїдальну криву, а саме її окремий випадок - кардіоїду.

Визначаємо оптимальне значення довжини радіуса коромислового диску, фазового кута та базовідстані, виходячи з обмеження розміру радіусу коромислового диску межами величини базовідстані та рівності колових швидкостей коромислового диску та кулачка в точці переходу від розбігу до вибігу. Це дозволяє отримати профіль без ділянки, на якій коромисловий диск обганяє по коловій швидкості кулачок.

Для оптимізації геометричних параметрів кулачкового механізму необхідно врахувати співвідношення та взаємозв'язок базовідстані, фазового та сумарного кута повороту та радіуса коромисловго диску, а також закон періодичного руху. Кут повороту веденої ланки задається конструктивно, закон періодичного руху вибирається по рекомендаціям [1], а зв'язок геометричних розмірів базовідстані та радіуса коромислового диску, а також фазового кута повороту кулачка визначається виразом:

$$
\mathrm{l}\left(\varphi+\gamma_{\Sigma} \cdot \mathrm{b}_{\mathrm{k}_{-} \max }\right)=\varphi \cdot \mathrm{b}
$$

де $b_{\text {k_max }}$ - максимальне біжуче значення інваріанта швидкості закону періодичного руху.

Залежність (2) дозволяє визначити оптимальні значення кожної з трьох необхідних величин.

Розрахунок радіусів-векторів кулачка механізму

Для розрахунків радіусів-векторів кулачка механізму періодичного повороту розглянемо схему (рис. 2), де $\mathrm{O}_{1} \mathrm{O}_{2}-$ базовідстань, O,A - радіус-вектор змінного профілю кулачка, $\mathrm{O}_{2} \mathrm{~A}$ - радіус коромислового диску.

З трикутника $\mathrm{O}_{1} \mathrm{O}_{2}$ А визначаємо радіуси-вектори змінного профілю кулачка:

$$
r_{k}=\sqrt{l^{2}+b^{2}-2 l b c o s\left(\gamma-\gamma_{k}\right)},
$$

де $\gamma_{\mathrm{k}}=\mathrm{a}_{\mathrm{k}} \gamma_{\mathrm{y}}-$ кутове переміщення коромислового диску; $\mathrm{k}=\frac{\mathrm{t}}{\mathrm{T}}$ - відносний час; $\mathrm{T}-$ період кінематичного циклу; $\gamma_{0}=\frac{\gamma_{\Sigma}}{2}-$ початковий кут положення коромисла відносно бази механізму; $a_{k}$ - інваріант переміщення коромислового диску. 


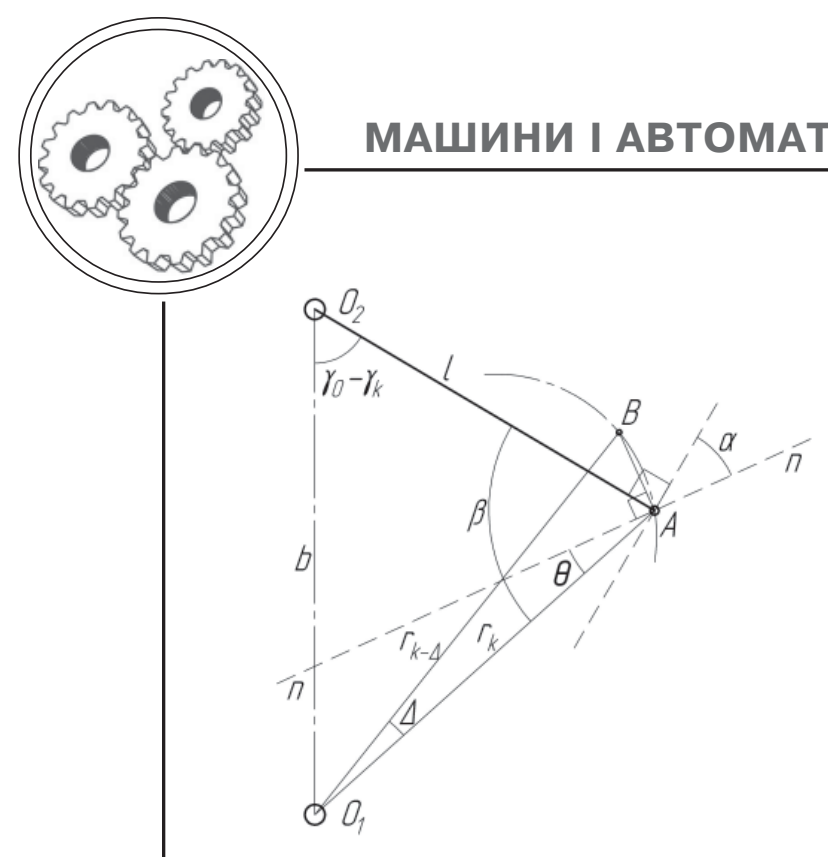

Рис. 2. Розрахункова схема кулачкового механізму періодичного повороту

Підставляючи відповідні параметри у формулу (3), отримаємо необхідні значення радіусів-векторів змінної ділянки профілю кулачка.

Визначення кутової поправки

Для забезпечення працездатності кулачкового механізму та виконання заданого закону повороту коромислового диску, який кінематично пов'язаний з веденою ланкою виконавчого механізму, необхідно враховувати величину кутової поправки. Кутова поправка виникає внаслідок зміщення ролика відносно початкового положення (рис. 3) і знаходиться $з$ виразу:

$$
\xi=\xi_{1} \mp \xi_{2},
$$

де $\xi_{1}$ - кут між початковим радіусом-вектором і базою, $\xi_{2}-$ кут між біжучим радіусом-вектором і

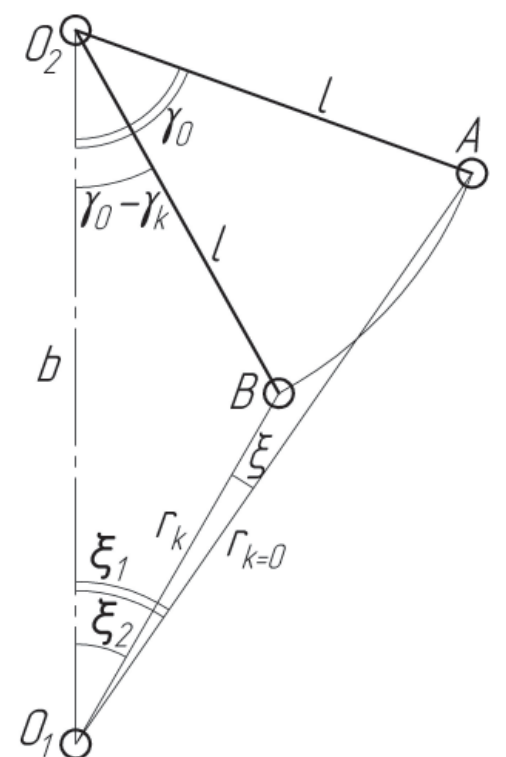

Рис. 3. Схема для визначення кутової поправки

базою. Кут тиску при розбігу веденої маси дорівнює їх різниці, а при вибігу - сумі.

Ці кути знаходимо з залежностей:

$$
\begin{gathered}
\xi_{1}=\arccos \frac{\mathrm{b}^{2}+\mathrm{r}_{0}^{2}-\mathrm{l}^{2}}{2 \mathrm{~b} \cdot \mathrm{r}_{0}}, \\
\xi_{2}=\arccos \frac{\mathrm{b}^{2}+\mathrm{r}_{\mathrm{k}}^{2}-\mathrm{I}^{2}}{2 \mathrm{~b} \cdot \mathrm{r}_{\mathrm{k}}}
\end{gathered}
$$

На рис. 4 представлено результат визначення значення кутової поправки в залежності від біжучого значення фазового кута.

Кутова поправка в залежності від сумарного кута повороту та базовідстані може приймати як від'ємні так і позитивні значення, що видно з графіку (рис. 4). 


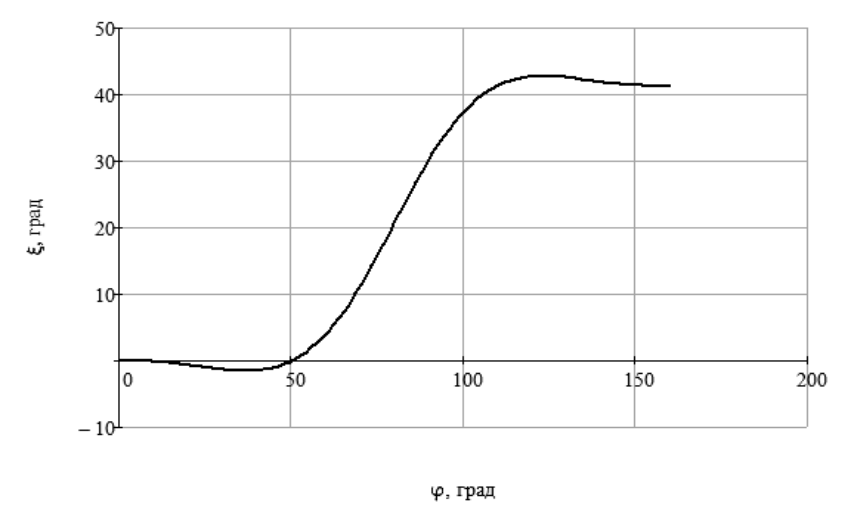

Рис. 4. Зміна значення кутової поправки в залежності від фазового кута

Однією з основних характеристик кулачкових механізмів $€$ кут тиску, який визначається як гострий кут, що утворюється вектором швидкості і лінією нормалі до теоретичного профілю кулачка у точці дотику. Від кута тиску залежать напруження в зоні контакту кулачок-ролик, крутні моменти на валу кулачка. Величина кута тиску не повинна перевищувати критичних значень, при яких можливе заклинювання і руйнування механізму.

Надійність роботи кулачкового механізму залежить від ступеня віддалення змінного кута тиску від кута заклинювання, який визначається:

$$
v_{m}=\frac{v_{a}}{k_{z}}
$$

де $\mathrm{k}_{\mathrm{z}}=1,25-1,75-$ коефіцієнт запасу згідно режиму роботи та захищеності механізму [1], $v_{\alpha}$ аварійний кут тиску для таких механізмів вибирається згідно рекомендацій $\left(v_{\mathrm{a}}=80^{\circ}\right)$ [4].

Значення поточного кута тиску визначаємо з геометричної схеми кулачкового механізму (див. рис. 2).

Відомо, що січна АВ буде дотичною до кривої у точці А $\mathrm{i}$, відповідно, пряма nn буде нормаллю до кривої в точці А у випадку, коли точка В буде наближатись до точки А. Чим меншим буде відрізок $A B$, тим точніше можна визначити кут нормалі до кривої. Довжина відрізку АВ задається кутом. Знаходимо кут:

$$
\beta=\arcsin \left(\frac{b \sin \left(\gamma_{0}-\gamma\right)}{r_{k}}\right) .
$$

Знаходимо відрізок АВ:

$$
A B=\sqrt{r_{k-\Delta}^{2}+r_{k}^{2}-2 r_{k-\Delta} r_{k} \cos \Delta} .
$$

Тоді біжучий кут підйому профілю між напрямком радіуса-вектора кулачка і лінією нормалі до теоретичного профілю кулачка у точці дотику визначається з виразу:

$$
\theta=\left|\frac{\pi}{2}-\arcsin \left(\frac{r_{k-\Delta} \sin \Delta}{A B}\right)\right|
$$

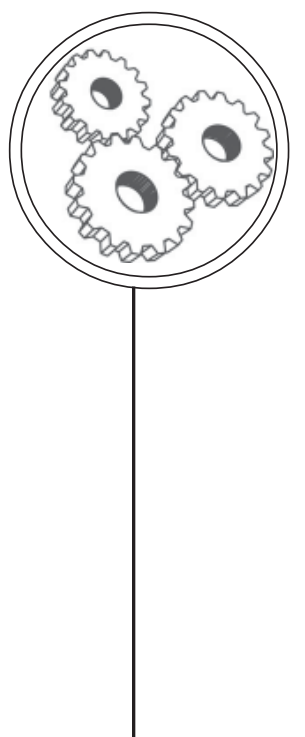


Біжучий кут тиску дорівнює:

$$
\alpha=\frac{\pi}{2}+\theta-\beta .
$$

\section{Визначення параметрів} роликової опори

Проведені дослідження показали, що значення радіусу кривини теоретичного профілю постійно зменшуються до точки переходу від розбігу до вибігу. Максимальне значення радіуса ролика рекомендується визначати графоаналітичним методом в точці переходу. Для цього встановлюємо три точки на малому куті, одна з яких є кінцевою точкою розбігу. Відповідно радіус кола, яке можна провести через ці точки, визначає максимальний радіус ролика. Координати точок в полярній системі координат визначаються $\mathrm{T} 1\left(\varphi_{1}, \rho_{1}\right), \mathrm{T} 2\left(\varphi_{2}, \rho_{2}\right), \mathrm{T} 3\left(\varphi_{3}, \rho_{3}\right)$ або в декартовій системі - T1 $\left(\mathrm{x}_{1}\right.$, $\left.\mathrm{y}_{1}\right), \mathrm{T} 2\left(\mathrm{x}_{2}, \mathrm{y}_{2}\right)$, T3 $\left(\mathrm{x}_{3}, \mathrm{y}_{3}\right)$, де $\mathrm{x}_{1}=$ $=\rho_{1} \cos \left(\varphi_{1}\right), y_{1}=\rho_{1} \sin \left(\varphi_{1}\right)$ і т.д. Радіус отриманого кола визначається по формулі:

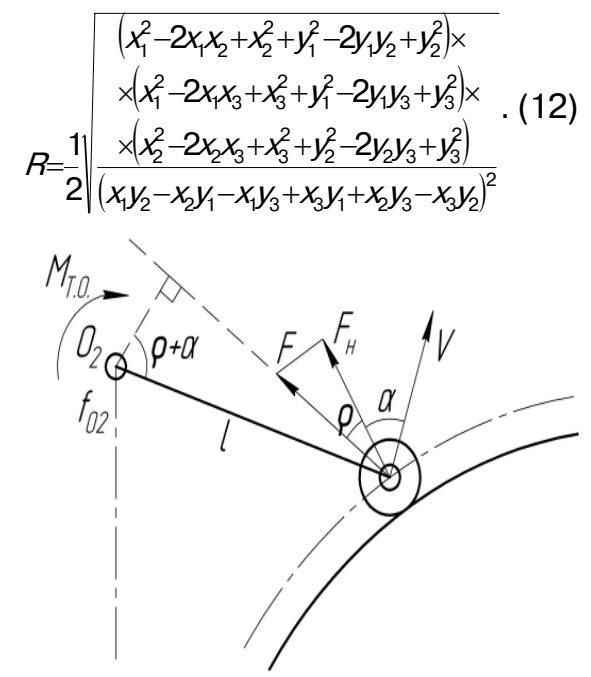

Рис. 5. Схема дії сил і моментів на коромисловий диск
Параметри роликової опори повинні задовольняти умовам міцності та зносостійкості $[1,4]$.

Розрахунок миттєвих значень ККД кулачкового механізму

При розрахунках кулачкових механізмів необхідно враховувати втрати енергії внаслідок тертя при передачі руху від двигуна до веденої ланки.

Для визначення миттєвих значень ККД розглянемо кулачкову пару, яка складається 3 двох складових: коромислового диску та кулачка.

Розглянемо умови рівноваги сил відносно осі обертання коромислового диску (рис. 5). 3 умови рівноваги моментів відносно осі обертання коромислового диску отримуємо залежність:

$$
M_{\text {т. }}=F \cdot / \cos (\rho+\alpha)-F \cdot r_{02} \cdot f_{02},
$$

де $\mathrm{M}_{\text {т.о. }}$ - момент технологічного опору, $f_{02}-$ коефіцієнт тертя в опорах коромислового диску, $\mathrm{r}_{02}$ - радіус тертя в підшипниках опор коромислового диску, $\mathrm{F}$ - сила, яка діє на кулачок 3 боку коромислового диску, с - приведений кут тертя.

Розглянемо умову рівноваги сил, що діють на кулачок (рис. 6). Знаходимо силу, яка діє на кулачок з боку коромислового диску з врахуванням приведеного кута тертя $\rho$ :

$$
F=\frac{F_{H}}{\cos \rho} .
$$

Ця сила створює момент відносно осі обертання кулачка $\left(\mathrm{M}_{1}\right)$ і викликає момент від сил тертя в опорах кулачка $\left(\mathrm{M}_{2}\right)$ : 


$$
\begin{gathered}
M_{1}=\frac{F_{H}}{\cos \rho} h, \\
M_{2}=\frac{F_{H}}{\cos \rho} r_{01} f_{01},
\end{gathered}
$$

де $\mathrm{h}=\mathrm{r}_{\mathrm{k}} \sin (\theta+\rho)-$ плече дії сили; $\mathrm{f}_{01}-$ коефіцієнт тертя в опорах кулачка; $r_{01}$ - радіус тертя в підшипниках вала кулачка; $\rho=\operatorname{arctanf}_{\mathrm{p}} ; \quad \mathrm{f}_{\mathrm{p}}=\frac{2 \mathrm{f}_{\text {тр_коч_рол }}}{\mathrm{D}_{\mathrm{p}}}+$
$+\frac{2 \mathrm{f}_{\text {тр_коч_шар }}}{\mathrm{d}}-$ приведений коефіцієнт тертя між кулачком і роликом; $\mathrm{f}_{\text {тр_коч_рол }}-$ коефіцієнт тертя кочення ролика по кулачку; $\mathrm{f}_{\text {тр_кочшар }}-$ коефіцієнт тертя кочення підшипника ролика.

Тоді умова рівноваги буде мати вигляд:

$$
\begin{gathered}
M_{k}=M_{1}+M_{2}= \\
=\frac{F_{H}}{\cos \rho}\left(r_{k} \sin (\theta+\rho)+f_{01} r_{01}\right) .
\end{gathered}
$$

Підставивши у формулу (16) значення формули (14), отримуємо:

$$
\begin{gathered}
M_{k}=\frac{M_{\text {T.o. }}}{\operatorname{lcos}(\rho+\alpha)-f_{02} r_{02}} . \\
\cdot\left(r_{k} \sin (\theta+\rho)+f_{01} r_{01}\right) .
\end{gathered}
$$

Після перетворення і заміни $\operatorname{tanr}=\mathrm{f}_{\mathrm{p}}$ формула набуде вигляду:

$M_{k}=\frac{M_{0.0}\left(r \sin \theta+r \cdot f_{p} \cos \theta+f_{01} r_{10} / \cos \rho\right)}{l \cos \alpha-f_{p} \cdot \mid \sin \alpha-f_{02} r_{0 R} / \cos \rho}$.

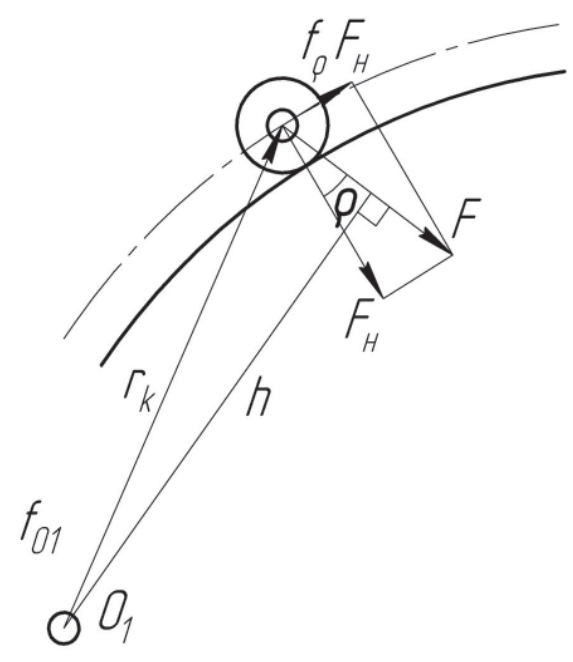

Рис. 6. Схема дії сил на кулачок

Для ідеального механізму $\mathrm{f}_{\mathrm{p}}=\mathrm{f}_{01}=\mathrm{f}_{02}=0$.

Тоді умова рівноваги ідеального механізму запишеться у вигляді:

$$
M_{k i}=\frac{M_{\text {T.o. }} r_{k} \sin \theta}{I \cos \alpha}
$$

Після підстановок і перетворення миттєвий ККД кулачкового механізму періодичного повороту визначається:

$\eta_{k}=\frac{1-f_{p} \tan \alpha-\frac{f_{02} r_{02}}{I \cos \alpha \cos \rho}}{1+f_{p} \tan \theta+\frac{f_{01} r_{01}}{r_{k} \sin \theta \cos \rho}} \cdot(20)$

Алгоритм розрахунку кулачкового механізму періодичного повороту

Для упорядкування розрахунків кулачкового механізму, визначення ЗПР запропоно- 

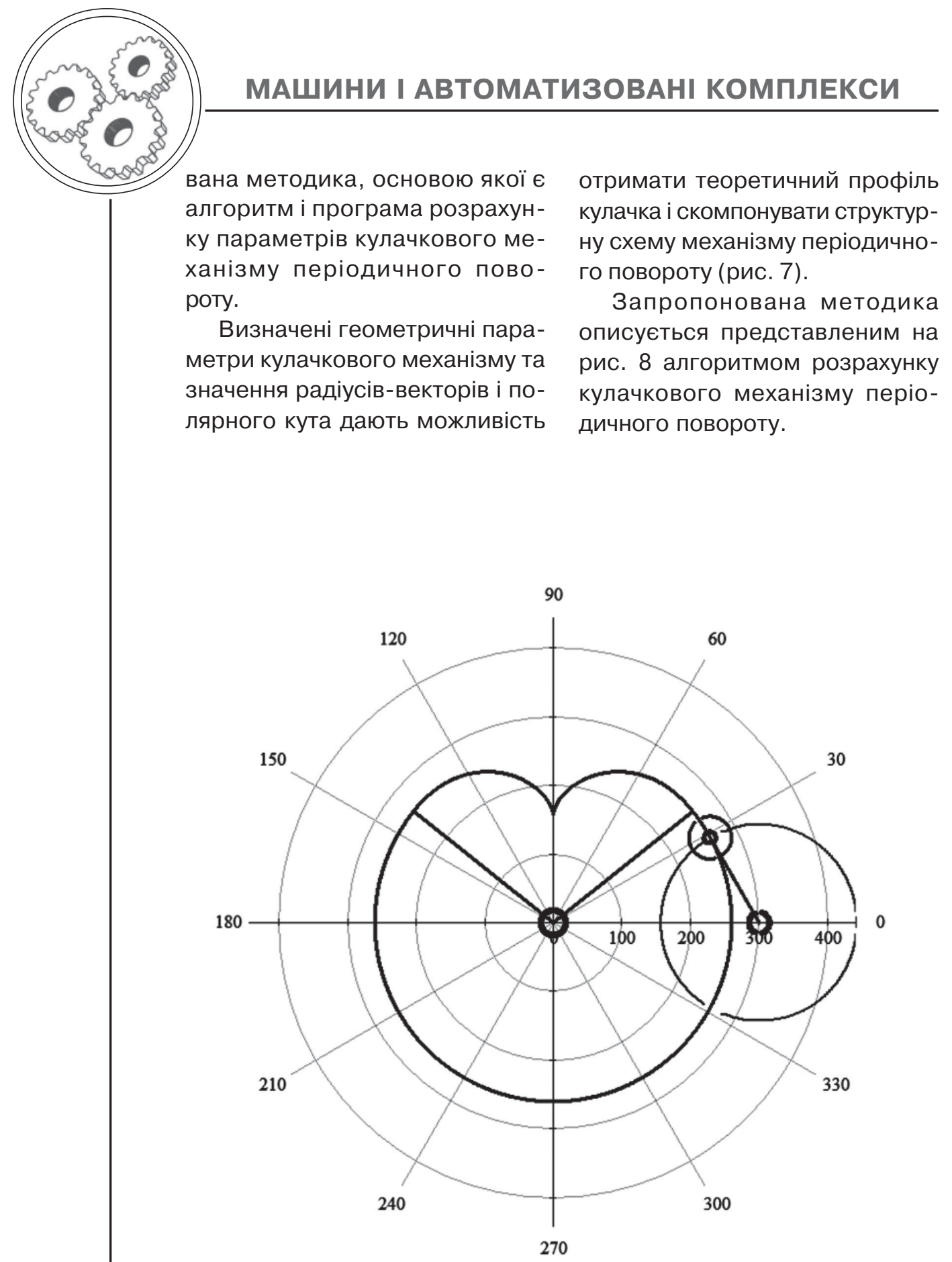

Рис. 7. Теоретичний профіль кулачка і структурна схема механізму періодичного повороту 


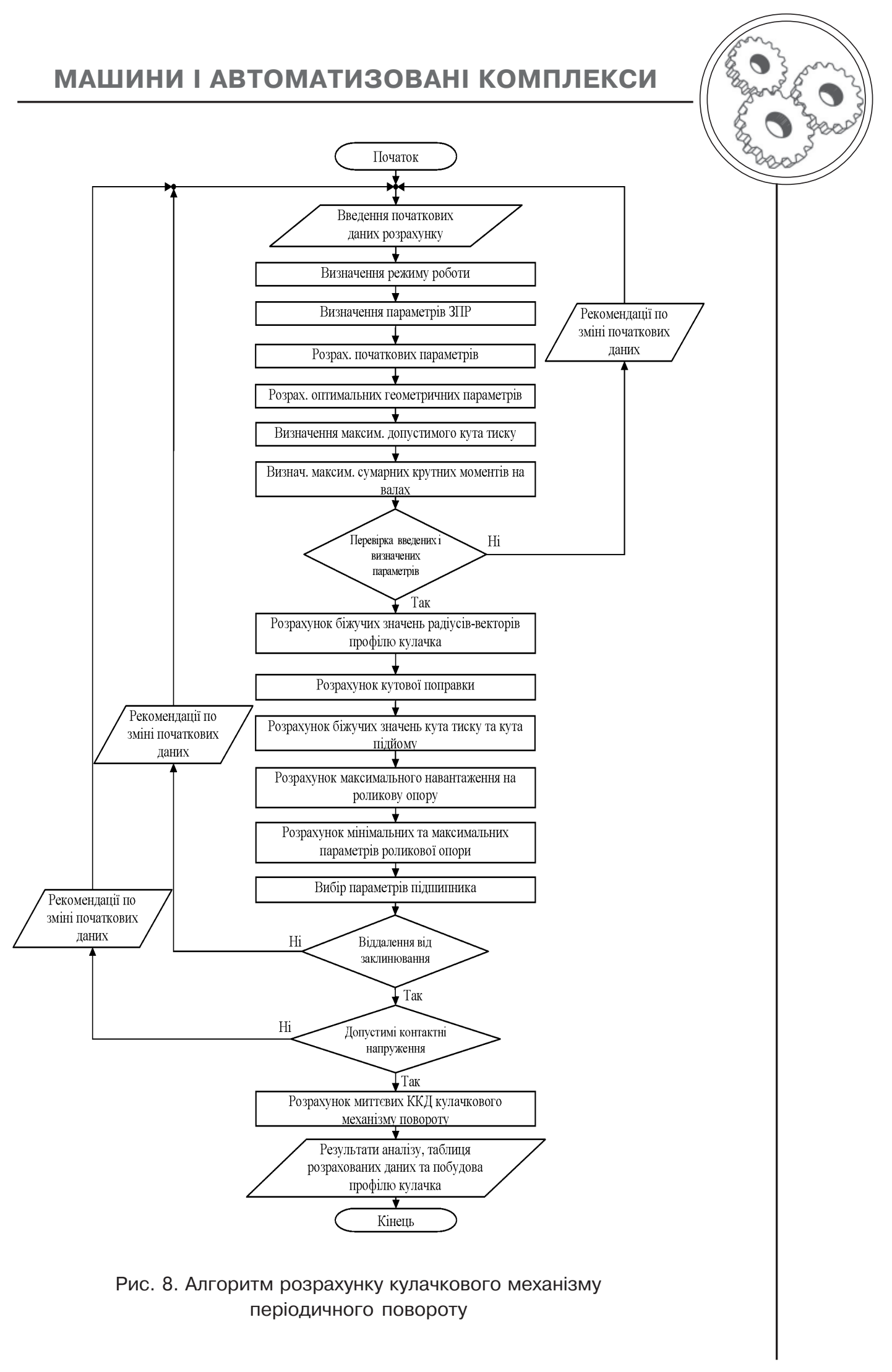




\section{МАШИНИ I АВТОМАТИЗОВАНІ КОМПЛЕКСИ}

\section{Висновки}

Запропонована методика i представлений алгоритм дозволяють виконати розрахунок параметрів кулачкового механізму періодичного повороту із забез- печенням точного відтворення заданого закону періодичного руху виконавчими ланками поліграфічних машин, а також визначити основні геометричні параметри механізму.

1. Полюдов О. М. Розрахунки циклових механізмів поліграфічних і пакувальних машин на персональному комп'ютері (теорія, програми, інструкції): навчальний посібник / Полюдов О. М., Кузнецов В. О., Коломієць А. Б. Львів : Вид-во УАД, 2004. - 94 с. 2. Гриценко Д. С. Динаміка привода крокового транспортера тамподрукарських машин // Збірник наукових праць «Комп'ютерні технології друкарства». - Л., 2011. - № 25. 3. Шостачук Ю. О. Дослідження точності позиціонування транспортувальних пристроїв конвеєрного типу тамподрукарської машини ТДМ-300 / Шостачук Ю. О., Гриценко Д. С. // Збірник наукових праць «Технологія і техніка друкарства». - К., 2011. - № 3(33). - С. 89-95. 4. К. В. Тир. Механика полиграфических автоматов / К. В. Тир. - М. : Книга, 1965.- 496 с.

Рецензент - Б. О. Черня, К.Т.н., доцент, НТУУ «КП|»

Надійшла до редакції 01.03.12 